\title{
Violent and
}

\section{aggressive patients}

\section{By Jane Merivale, Senior Dento-legal Advisor, BDA Indemnity}

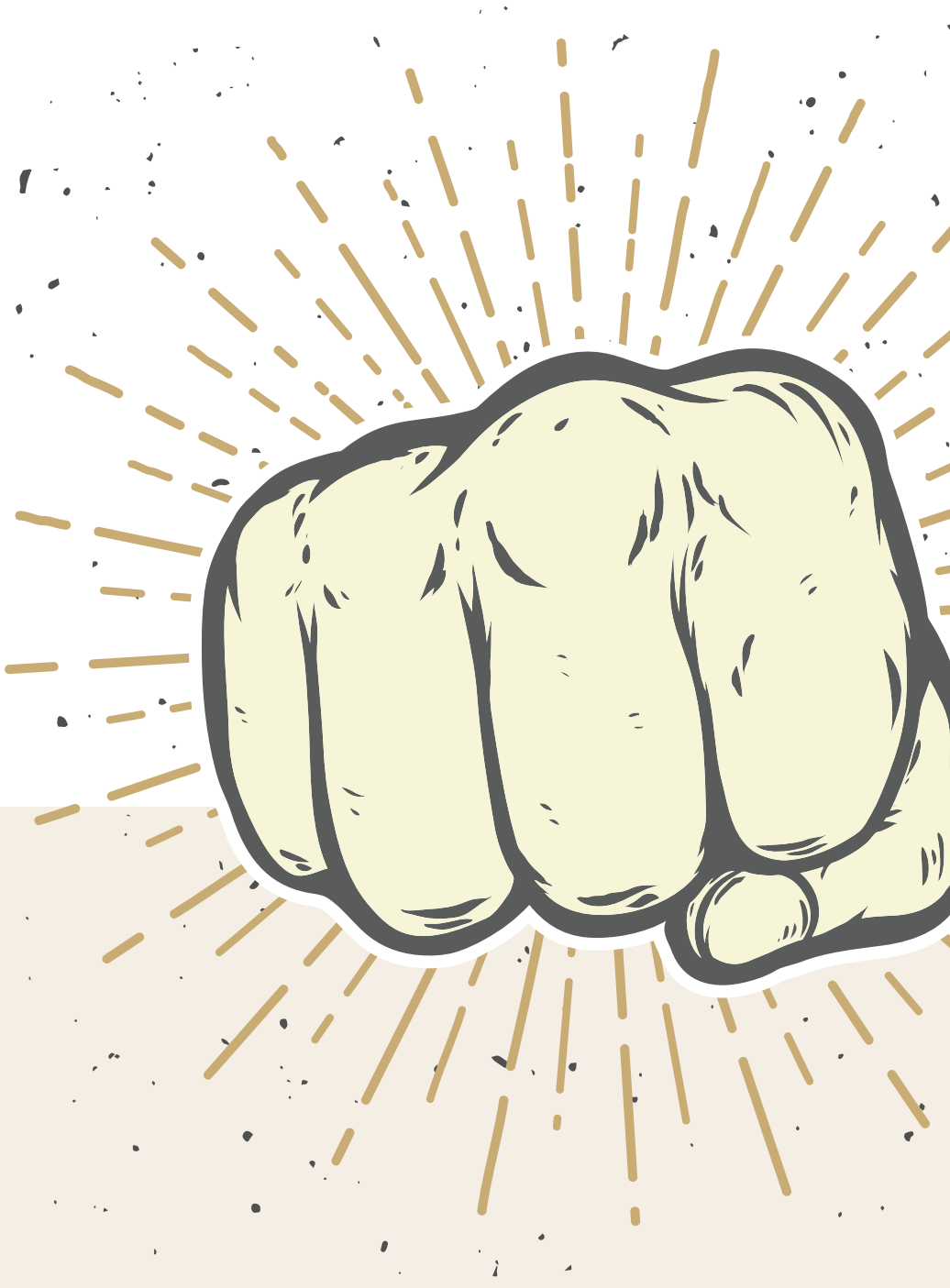

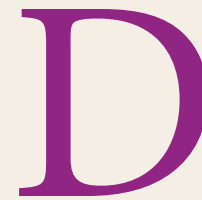

espite advances in modern dentistry, people rarely look forward to dental treatment and unsurprisingly the dental team is regularly confronted by patients demonstrating a range of challenging behaviours. These will span a continuum from merely unpleasant, borderline abuse through to aggression and occasionally, violence.

\section{Behaviour}

We need to understand the reasons behind such behaviour and factor them into our management of the patient. For example, some may have mental health issues, have a history of violence or other personal factors causing stress, such as relationship breakdown, death of a family member, friend or loss of a job and for our part, we need to learn how to be sensitive and address such conduct. However, there will be times when the behaviour is simply unacceptable, treatment cannot be provided, and the dental team needs protecting. Ultimately it is a judgement call to determine what constitutes 'unacceptable' and the tipping point will vary according to the experience and interactional skills of the team and their ability to manage a difficult situation.

\section{Take no risks}

The media is currently awash with high profile stories of violence, including knife crime, and no-one should be overly worried or complacent when it comes to personal and public safety. Across the entire NHS there is a policy of zero tolerance of abusive and threatening behaviour towards its staff. In the most recent NHS Staff Survey, $14.5 \%$ of responders reported being subject to violence from patients and their families or the general public. This is the highest figure for five years and cannot be ignored. The government is aware of the problem and in October 2018 introduced a violence reduction strategy. This includes the CQC scrutinising violence as part of their inspection regime, improving staff training to deal with violence, including circumstances involving patients with dementia or mental illness. It also involves the NHS working with the police and Crown Prosecution Service to help victims of violence give evidence and bring a prosecution quickly and efficiently.

\section{Information}

Regardless of the contract under which patients are treated, each practice should have an understandable policy displayed and readily available to patients, setting out a policy of zero tolerance of abuse and violence. The entire team needs to be conversant with the policy and trained in its implementation. Detailed notes must be made of the difficulties encountered and steps taken to support any decisions made, if challenged.

\section{Alerts}

A patient's behaviour can seem particularly unpredictable if they are new and hence unknown to the practice. However, experience teaches us that there are clues to be had; it is not always what patients say, as their body language can alert the team to a situation that could escalate. If a patient becomes overtly hostile and the team is fearful, then the police should be called; some practices install a panic button for such an eventuality. 


\title{
'A patient's behaviour can seem
}

\section{particularly unpredictable if they}

\author{
are new and hence unknown to the
}

practice. However, experience teaches

us that there are clues to be had...'

Discontinuation and termination

The practice staff needs to understand that those in the team who are regulated by the GDC have various obligations and accountabilities placed on them which will engage when managing violent and aggressive patients.

The professional relationship is a fiduciary one: built on trust and mutual understanding, encompassing both legal and ethical duties. As such, obligations apply to both the registrant and practitioner. These include a degree of cooperation and conduct which allows treatment to take place with respect afforded to both parties. The extent of these obligations will vary in terms of the practice context and the age of the patients being treated.

Fundamental to delivering dental care is an emphasis to act in the patient's best interests, not to 'abandon' patients solely on the basis of them raising concerns.

There is an expectation that team members will acquire the necessary skills to address difficult behaviour, as this is part and parcel of the provision of dental care; fear and pain affect all of us and dental care professionals become accustomed to suppressing their emotional empathic capacity to be able to offer the best treatment to those in pain and whose behaviour may temporarily be out of character.

This is a far cry from an episode of escalating patient aggression when steps should be taken without delay to protect the team.

In less heated circumstances when the professional relationship has broken down due to obnoxious or abusive behaviour then, having informed the patient of the practice policy and requirements, the option exists to discontinue treatment whilst trying to establish a reciprocity. Failing this, the relationship may be terminated formally; this decision rests with the practice principal.

Here the GDC's Standards Guidance 1.7.8 applies:

'In rare circumstances, the trust between you and a patient may break down, and you may find it necessary to end the professional relationship. You should not stop providing a service to a patient solely because of a complaint the patient has made about you or your team.
Before you end a professional relationship with a patient, you must be satisfied that your decision is fair and you must be able to justify your decision. You should write to the patient to tell them your decision and your reasons for it. You should take steps to ensure that arrangements are made promptly for the continuing care of the patient.'

Likewise, the Standard General Dental Services Contract sets out the contractual position regarding violent patients seen under the NHS.

\section{Summary}

Develop the skills to identify the difference between difficult behaviour that can be managed within the practice and unacceptable behaviour that does not have to be tolerated. Never hesitate to seek advice from your professional indemnity organisation in these circumstances; those with experience and a step removed from the difficulties can offer invaluable help.

https://doi.org/10.1038/s41407-020-0376-z: 